\title{
Optimization and Performance Analysis of Rail-Train Coupling System with Inerters
}

\author{
Shichang Han $\mathbb{D}^{1}{ }^{1}$ Xian Wang $\mathbb{D},{ }^{1}$ Chunxi Yang $\left(\mathbb{D},{ }^{1}\right.$ Guowei Xie $\mathbb{D}^{2},{ }^{2}$ Zhongcheng Qiu $\mathbb{D}{ }^{1}$ \\ and Chen Wang ${ }^{1}$ \\ ${ }^{1}$ Faculty of Mechanical and Electrical Engineering, Kunming University of Science and Technology, Kunming 650500, China \\ ${ }^{2}$ Shanghai Headquarters, QST Corporation, Shanghai 201210, China \\ Correspondence should be addressed to Xian Wang; 375835425@qq.com
}

Received 5 March 2021; Accepted 22 April 2021; Published 8 May 2021

Academic Editor: Youmin Zhang

Copyright ( 2021 Shichang Han et al. This is an open access article distributed under the Creative Commons Attribution License, which permits unrestricted use, distribution, and reproduction in any medium, provided the original work is properly cited.

\begin{abstract}
Optimization for vertical vibration performance of a rail-train coupling system is investigated in this paper with the introduction of inerters for both primary and secondary suspensions. A model of a typical Chinese passenger train that travels on a traditional rail with track, sleepers, and ballast is simulated. The goal is to improve the ride quality for the train and vibration attenuation for the rail system in response to track irregularities. Optimizations for only inertance and all suspension parameters are carried out by the particle swarm algorithm (PSO). Performance benefits for both the train and the rail system are demonstrated and suspension layouts with inerters connected in parallel and series are compared with the traditional one in both time domain and frequency domain.
\end{abstract}

\section{Introduction}

Vertical performance of a train when it travels on a track is an important index for the running quality, such as the riding comfort for a passenger train. Improvement of the performance has been explored for years. And, the parameters optimization of the train or rail system has been proven useful by using many methods. Optimization of a light rail vehicle was done by Pombo et al. [1] using the direct multisearch (DMS) method with consideration of a curve and slope rail to get better running safety and ride quality. In the study by [2], the suspension parameters of high-speed rail vehicles are obtained via the Taguchi robust optimization method leading to an obvious improvement in the vertical running stability of the vehicle under different running conditions. And, Liu et al. [3] dealt with multiobjective optimization for the suspension parameters of railcars and proposed an optimization strategy combining the collaborative optimization method and the metamodel method. The results show that the dynamic performance of railcars is improved remarkably with the robust collaborative optimization of the suspension parameters. In paper [4], using a combination of multibody dynamics and a genetic algorithm (GA), the curving performance of a transit rail vehicle model with 21 degrees of freedom was optimized, where the optimal design variables were searched for minimizing the noise or wear arising from misalignment of the wheelsets with the track. Wang et al. [5] used the improved sequential quadratic programming (SQP) method to generate a sequence of improving profiles to improve vehicle running stability in the switch panel of highspeed railway turnouts, which would decrease the rolling radii difference. Furthermore, in study [6], Dullinger took both GA and SQP for multiobjective optimization of the traction system configuration of trains' decision variables. And, the particle swarm optimization (PSO) algorithm was used by Sun [7] to optimize the parameters of suspensions. The advantages of PSO, which are simple programming and fast searching speed, have been proven efficienct in the suspension optimization.

Some modelling and control strategies can also benefit the performance of a system [8-10], even when there are some uncertainties $[11,12]$. However, on comparing the cost 
of the system modelling and control, structure improvement can be more practical. A mechanical network element called inerter is reported these days since it was brought out by Smith [13] and successfully used to benefit a car suspension [14]. Great interest has been put in inerters from different fields such as car suspensions, energy sink [15], isolation system [16], and civil engineering [17]. Rail vehicles with inerters are also explored. Wang $[18,19]$ investigated the performance benefits of train suspension systems employing an inerter in both vertical performance and lateral stability. Passenger comfort, dynamic wheel load, and critical speed were evaluated with different inerter combinations. Wang et al. [20] also constructed a 28 degree-of-freedom train model with inerters to investigate the critical speed, settling time, and passenger comfort for a full train system. Jiang $[21,22]$ focused on the improvement of rail vehicle performance with inerters in both lateral and vertical suspension systems. In [21], a two-axle single-stage railway vehicle was investigated under track irregularities. And, in [22], the lateral body movement of the vehicle when entering a curved track was considered in the lateral direction.

Research studies have proven that either parameters optimization or inerters are of great benefits to the performance of rail vehicles, which will be a novel way to optimize the train problems. However, few reported the effect on the rail when the inerter-equipped train travels over. This paper firstly considers a typical Chinese passenger train on active duty and uses PSO to optimize its first and second suspension parameters for better ride comfort and suspension displacements, while inerters are introduced in both suspensions. Then, a rail-train coupling system is introduced to evaluate the effect of the optimization parameters to the rail system which consists of rail, sleepers, and ballast.
This paper is organized as follows: in Section 2, a 10degree of freedom and a 16-degree of freedom train models with contact force are described. Different suspension layouts with inerters, which are parallel and series connected, are considered. Section 3 shows optimization of the suspension parameters to minimize the ride comfort and suspension displacements. Section 4 describes the performance of the rail-train coupling system. The acceleration of rail, sleepers, and ballast is discussed in different suspension layouts. Lastly, some conclusions are made in Section 5.

\section{System Description}

Although nowadays the high-speed railway develops rapidly, our national rail net is mostly served by the traditional railway, which consists of rail, sleepers, and ballast. So, analysis of a traditional railway is still of important worth. And, a commonly seen passenger train is also considered in this paper. The rail-train coupling system is established the same as in the research of Zhai [23]. Figure 1 shows the railtrain system, in which the train model consists of one car body, two bogies and four wheelsets, and the rail model consists of rail, uniformly distributed sleepers and ballast underneath. Only vertical direction is focused in the following sections.

2.1. Model of the Rail System. As shown in Figure 1, rail, sleepers, and ballast are all considered in the rail system in this paper. The rail is modelled as a continuous Euler beam with discrete sleeper supports which can be expressed as follows [23]:

$$
E I \frac{\partial^{4} Z_{r}(x, t)}{\partial x^{4}}+m_{r} \frac{\partial^{2} Z_{r}(x, t)}{\partial t^{2}}=-\sum_{i=1}^{N} F_{r s i}(t) \delta\left(x-x_{i}\right)+\sum_{j=1}^{4} p_{j} \delta\left(x-x_{w j}\right)
$$

where $E I$ is the rail beam bending stiffness $\left(\mathrm{N} \cdot \mathrm{m}^{2}\right), Z_{r}$ is the vertical displacement of the rail $(\mathrm{m}), x$ is the location of the rail $(\mathrm{m}), x_{i}$ is the location of the $i^{\text {th }} \operatorname{rail}$ pad $(\mathrm{m})$, which supports the rail, $x_{w j}$ is the location of the $j^{\text {th }}$ wheel $(\mathrm{m})$, where contact force between the wheel and rail exists, $F_{r s i}$ is $i^{\text {th }}$ rail pad supporting force $(\mathrm{N})$, and $p_{j}$ is the $j^{\text {th }}$ wheel-rail contact force $(\mathrm{N}) . \delta$ denotes the Dirac function. And, the other parameters can be found in Table 1 .

the sleepers are modelled as uniformly distributed. It can be expressed easily by the Newton-Euler approach. On the contrary, the ballast is modelled as a discrete ballast mass according to [23]. The expression of the discrete ballast mass $M_{b}$ is as follows:

$$
M_{b}=\rho_{b} V_{b}=\rho_{b} h_{b}\left[l_{e} l_{b}+\left(l_{e}+l_{b}\right) h_{b} \tan \alpha+\frac{4}{3} h_{b}^{2} \tan ^{2} \alpha\right],
$$

where all the meaning of parameters can be found in Table 1. And, it is worth to mention, in this paper, the ballast mass is discrete and has no overlapping since standard sleeper spacing is taken.

The three layers of springs and dampers represent the elasticity and damping of the rail pad, the ballast, and the subgrade, respectively. By using the Ritz method [24], equation (1) of the rail can be converted into the second-order ordinary differential equation. The system dynamics equations of the rail, sleeper, and ballast can be established by the Newton-Euler approach and are shown in the appendix. Table 1 shows the parameters of the rail in the equations.

2.2. Train Model and Suspensions with the Inerter. As shown in Figure 1, one car body, two bogies, and four wheelsets are modelled. 10 degrees of freedom are considered, as shown in Table 2.

Springs and dampers between wheels and bogies represent the elasticity and damping of the primary suspension, 


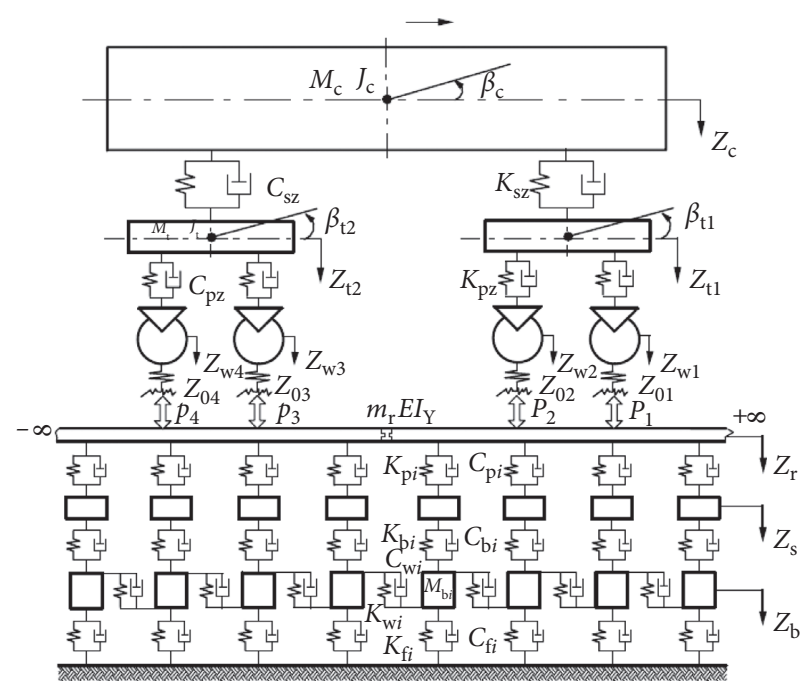

FIgURE 1: A rail-train coupling model [23].

TABle 1: Parameters of the rail system.

\begin{tabular}{|c|c|c|c|}
\hline Symbol & Parameter & Unit & $\begin{array}{l}\text { Nominal } \\
\text { value }\end{array}$ \\
\hline E & Elastic modulus of rail & $\mathrm{N} / \mathrm{m}^{2}$ & $2.059 \times 10^{11}$ \\
\hline$I$ & Rail cross-sectional inertia & $\mathrm{m}^{4}$ & $3.217 \times 10^{-5}$ \\
\hline$m_{r}$ & Rail mass per unit length & $\mathrm{kg} / \mathrm{m}$ & 60.64 \\
\hline$m_{s}$ & Sleeper mass (half) & $\mathrm{kg}$ & 125.5 \\
\hline$K_{p}$ & Rail pad stiffness & $\mathrm{N} / \mathrm{m}$ & $1.0 \times 10^{8}$ \\
\hline$C_{p}^{P}$ & Rail pad damping & $\mathrm{N} \cdot \mathrm{s} / \mathrm{m}$ & $7.5 \times 10^{4}$ \\
\hline$l_{s}^{r}$ & Sleeper spacing & $\mathrm{m}$ & 0.545 \\
\hline$l_{e}$ & $\begin{array}{c}\text { Effective support length of half } \\
\text { sleeper }\end{array}$ & $\mathrm{m}$ & 0.95 \\
\hline$l_{b}$ & Sleeper bottom width & $\mathrm{m}$ & 0.273 \\
\hline$\rho_{b}$ & Ballast density & $\mathrm{kg} / \mathrm{m}^{3}$ & $1.8 \times 10^{3}$ \\
\hline$E_{b}$ & Elastic modulus of ballast & $\mathrm{N} / \mathrm{m}^{2}$ & $1.1 \times 10^{8}$ \\
\hline$C_{b}$ & Ballast damping & $\mathrm{N} \cdot \mathrm{s} / \mathrm{m}$ & $5.88 \times 10^{4}$ \\
\hline$K_{w}$ & Ballast shear stiffness & $\mathrm{N} / \mathrm{m}$ & $7.84 \times 10^{7}$ \\
\hline$C_{w}$ & Ballast shear damping & $\mathrm{N} \cdot \mathrm{s} / \mathrm{m}$ & $8 \times 10^{4}$ \\
\hline$\alpha$ & Ballast stress distribution angle & $\left({ }^{\circ}\right)$ & 35 \\
\hline$h_{b}$ & Ballast thickness & $\mathrm{m}$ & 0.35 \\
\hline$E_{f}$ & Subgrade K30 modulus & $\begin{array}{c}\mathrm{MPa} / \\
\mathrm{m}\end{array}$ & $1.9 \times 10^{8}$ \\
\hline$C_{f}$ & Subgrade damping & $\mathrm{N} \cdot \mathrm{s} / \mathrm{m}$ & $1.0 \times 10^{5}$ \\
\hline
\end{tabular}

TABLE 2: 10 degrees of freedom of the train.

\begin{tabular}{lcc}
\hline Component & Translational motion & Pitch motion \\
\hline Car body & $Z_{c}$ & $\beta_{c}$ \\
Bogie & $Z_{t i}(i=1 \sim 2)$ & $\beta_{t i}(i=1 \sim 2)$ \\
Wheelsets & $Z_{w i}(i=1 \sim 4)$ & - \\
\hline
\end{tabular}

and those between car body and bogies represent the secondary suspension of the train. The traditional suspension consists of a parallel combination of a spring and a damper. To make the basic understanding of the effect by the inerter, only one inerter is added in each suspension. It is arranged in parallel or series with the damper, as shown in Figure 2.

In this paper, the parallel or series layout will be investigated separately, which means the same type of layout will be added in all suspensions at the same time. So, the dynamic equations can be obtained as in the appendix. The equations of the traditional suspension are omitted since it will be same as the parallel equations when $b=0 \mathrm{~kg}$. On the contrary, an extra freedom between the inerter and damper should be considered when they are series connected. The train model with the series-connected inerter has 16 degrees of freedom with 6 suspension's extra freedom. All the parameters of the train are given in Table 3.

2.3. Contact Force between the Wheel and Rail. There are mainly normal force and creep force in the wheel-rail interaction. However, analysis of vertical performance can neglect the creep force with only normal force in consideration. In this case, the normal force, which is the contact force between the wheel and rail, can use the nonlinear Hertzian elastic contact theory to model. The nonlinear Hertzian elastic contact theory has been applied for the wheel-rail contact for years because of its easy calculation and high accuracy [25].

To calculate the normal force, the wheel-rail normal elastic compressing deformation at each contact point at every moment must be obtained. The equation of the theory is

$$
p(t)=\left[\frac{1}{G} \delta Z(t)\right]^{(3 / 2)},
$$

where $G$ is the wheel-rail contact coefficient $\left(\mathrm{m} / \mathrm{N}^{2 / 3}\right)$ and $\delta Z(t)$ is the elastic compressing deformation $(m)$. In this paper, the wheel with cone tread is selected, so the wheel-rail contact coefficient is $G=4.57 R^{-0.149} e^{-8}$, in which $R$ is wheel radius.

When only vertical direction is considered, the compressing deformation equals to the vertical relative displacement of the wheel and rail. The expression is as follows:

$$
\delta Z(t)=Z_{w}(t)-Z_{r}\left(x_{w}, t\right)-Z_{0}(t),
$$

where $Z_{w}(t)$ is the vertical displacement of the wheel (m), $Z_{r}\left(x_{w}, t\right)$ is the vertical displacement of the rail under the wheel $(m)$, and $Z_{0}(t)$ is the rail irregularity in the vertical direction. When the compressing deformation is analysed, it can be applied for 4 wheels using a time delay. The time delay is simply calculated by distances between each wheel divided by the traveling speed of the train. If the time for the first wheel is $t_{w 1}=t_{0}$, then, $t_{w 2}=t_{0}+\left(2 l_{t} / v\right), t_{w 3}=t_{0}+\left(2 l_{c} / v\right)$, and $t_{w 4}=t_{0}+\left(2\left(l_{c}+l_{t}\right) / v\right)$, where $v$ is the speed of the train.

\subsection{System Input and Equation-Solving Method}

2.4.1. System Input. Since the different directions of motion are weakly coupled in the rail-train system, the height irregularity, which mainly affects the vertical motion of the system, is only considered as the system input. A height irregularity power spectral density (PSD) obtained by Federal Railway Administration of America is introduced in this paper. The expression is 


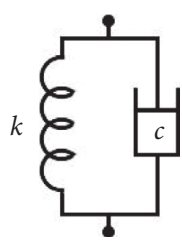

(a)

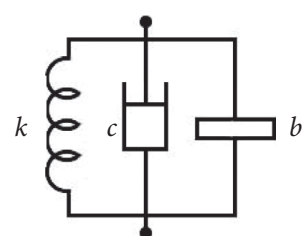

(b)

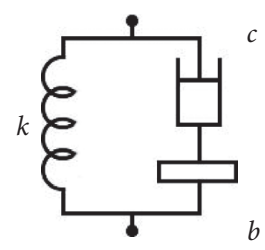

(c)

Figure 2: Suspension candidates with the inerter. (a) Traditional one. (b) Parallel one. (c) Series one.

TABle 3: Parameters of the train model.

\begin{tabular}{lccc}
\hline Symbol & Parameter & Unit & Nominal value \\
\hline$m_{c}$ & Vehicle body mass & $\mathrm{kg}$ & 38500 \\
$m_{t}$ & Bogie frame mass & $\mathrm{kg}$ & 2980 \\
$m_{w}$ & Wheelset mass & $\mathrm{kg}$ & 1350 \\
$J_{c}$ & Vehicle pitch inertia & $\mathrm{kg} \cdot \mathrm{m}^{2}$ & $2.446 \times 10^{6}$ \\
$J_{t}$ & Bogie pitch inertia & $\mathrm{kg} \cdot \mathrm{m}^{2}$ & 3605 \\
$K_{p z}$ & Primary suspension stiffness per axle box & $\mathrm{N} / \mathrm{m}$ & $2.14 \times 10^{6}$ \\
$K_{s z}$ & Secondary suspension stiffness & $\mathrm{N} \cdot \mathrm{s} / \mathrm{m}$ & $2.535 \times 10^{6}$ \\
$C_{p z}$ & Primary suspension damping per axle box & $\mathrm{N} \cdot \mathrm{s} / \mathrm{m}$ & $4.9 \times 10^{4}$ \\
$C_{s z}$ & Secondary suspension damping & $\mathrm{m}$ & $1.96 \times 10^{5}$ \\
$l_{c}$ & Semilongitudinal spacing of vehicle & $\mathrm{m}$ & 8.4 \\
$l_{t}$ & Semilongitudinal spacing of bogie & $\mathrm{m}$ & 1.2 \\
$R$ & Wheel radius & $\mathrm{m}$ & 0.4575 \\
\hline
\end{tabular}

$$
S_{v}(\Omega)=\frac{k A_{v} \Omega_{c}^{2}}{\Omega^{2}\left(\Omega^{2}+\Omega_{c}^{2}\right)} .
$$

In which, $\Omega$ is the spatial frequency of track irregularity $(1 / \mathrm{m}), k$ is the safety number, $A_{v}$ is the roughness constant $\left(\mathrm{cm}^{2} \cdot \mathrm{rad} / \mathrm{m}\right)$, and $\Omega_{c}$ is the cut-off frequencies $(\mathrm{rad} / \mathrm{m})$.

According to the rail PSD parameters, a class 6 rail is selected with allowed max speed of $176 \mathrm{~km} / \mathrm{h}$. The roughness constant is $A_{v}=0.0339 \mathrm{~cm}^{2} \cdot \mathrm{rad} / \mathrm{m}$, and the cut-off frequencies is $\Omega_{c}=0.8245 \mathrm{rad} / \mathrm{m}$. And, we use a safety number $k=2.5$. In this paper, the speed takes a middle value of the speed range as $90 \mathrm{~km} / \mathrm{h}$, which is also a normal speed used in reality. The time-domain irregularity can be transformed from PSD by using the trigonometric series method [26], as shown in Figure 3.

2.4.2. Numerical Method for Equation Solving. From Section 2.1 to 2.3 , the equations of the rail-train coupling system can be expressed as a unified matrix form as follows:

$$
M \ddot{X}+C \dot{X}+K X=F,
$$

where $M, C$, and $K$ are the mass (including inerters), damping, and stiffness matrices and $F$ is the forces of the system.

However, the size of the matrix depends on the number of the system's degrees of freedom. Take the mass matrix for example, it will consist of the train body, bogies, wheelsets, modes of rail, sleepers, and discrete ballasts. The size will equal the total number of them. Such a large matrix transformation and calculation is hard to be solved in the theoretical way. So, the step-by-step time integration method will be used to solve the equations of the system. In this paper, the method in [27] is used, which is successfully applied in the field of analysis of vehicle-track coupled dynamics. The basic scheme is constructed as follows:

$$
\left\{\begin{array}{l}
\{X\}_{n+1}=\{X\}_{n}+\{v\}_{n} \Delta t+\left(\frac{1}{2}+\psi\right)\{A\}_{n} \Delta t^{2}-\psi\{A\}_{n-1} \Delta t^{2}, \\
\{v\}_{n+1}=\{v\}_{n}+(1+\varphi)\{A\}_{n} \Delta t-\varphi\{A\}_{n-1} \Delta t
\end{array}\right.
$$

where $n$ indicates the steps and $\psi$ and $\varphi$ are parameters that control the stability and numerical dissipation of the algorithm; we take $\psi=0.25$ and $\varphi=0.5$ in this paper. In addition, to keep the stability of the integration, time steps are used in $10^{-5} \mathrm{~s}$ for train analysis and optimization, and $10^{-6} \mathrm{~s}$ for rail-train coupling system analysis. The error to control the integration uses 0.1 .

\section{Optimization of Suspension Performance}

3.1. Optimization of Suspension Parameters. Once an inerter is arranged in the suspension layout, the parameters should be identified. The PSO is taken to do the optimization of the suspension parameters. A simplification is made here that, due to the complexity the rail system brings to the matrix and all the optimizing parameters are of the suspension of the train, only the train model is used to do the optimization. The objective of this procedure is to minimize the train body acceleration for better riding comfort and less primary suspension displacement.

For the riding comfort, the RMS value of the train body acceleration $a_{t b}$ is used as an index with the comparison of the traditional suspension $a_{t b 0}$. On the contrary, the less the primary suspension displacement is, the less the force 


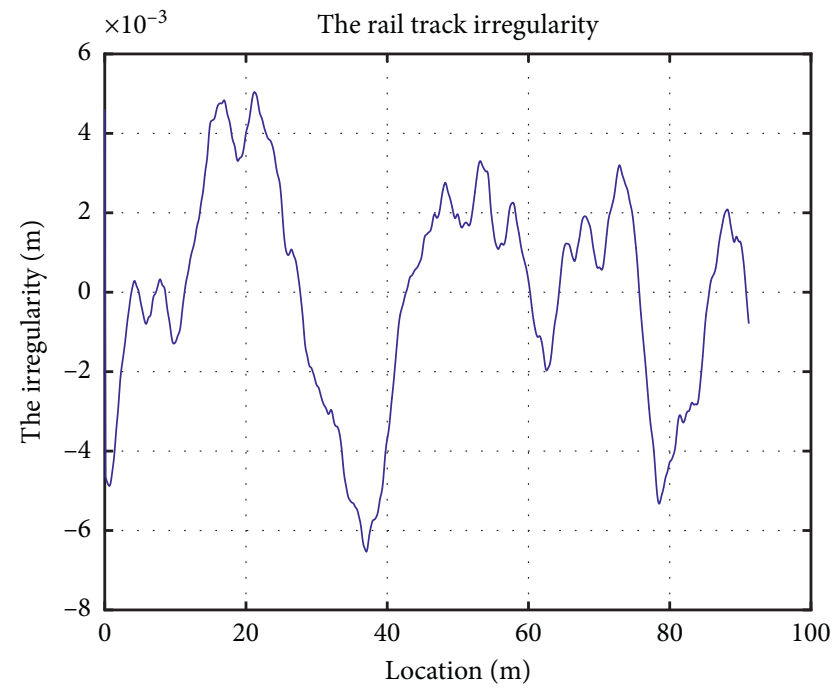

FIgURE 3: Track irregularity of class 6.

applied on the wheelsets will be, which are contacted with the rail. So, the RMS value of primary suspension displacements $x_{p}$ will be mainly focused. For the optimizing procedure, the train body acceleration and primary suspension displacements are equally considered. So, their weight in the optimization will be 0.5 for each value. Furthermore, all primary suspension displacements of four wheels are taking an equal weight, which is 0.125 out of 0.5 . The optimized objective function can be written as follows:

$$
\min Y=0.5 \times \frac{a_{t b}}{a_{t b 0}}+\sum_{i=1}^{4} 0.125 \times \frac{x_{p i}}{x_{p i 0}} .
$$

In which, $i$ stands for the number of the wheelset, $x_{p i}$ is the primary suspension displacement on the $i^{\text {th }}$ wheel, and $x_{p i 0}$ is that of the traditional one. For all the parameter range of stiffness $K$ and damping $C$, the upper and lower limits are roughly $30 \%$ up and down the parameters of the traditional suspension, as shown in Table 4 . For the inerter's value $B$, a range of $0-60000 \mathrm{~kg}$ is used during the optimization.

Optimization is carried out by two steps. First, keep the $K$ and $C$ their traditional value and optimize inertance $B$ only; Table 5 shows the optimal values of the inerters in parallel and series layouts. And, the second step optimizes all the values of $K, C$, and $B$. The optimized parameters are shown in Table 6. It is also worth to mention that the primary suspensions are considered the same in the front and rear bogies.

3.2. Performance Verification. From Section 3.1, optimization is carried out in two cases. Both two cases are studied in this section to verify the performance and find a better parameter setting for the next coupling system analysis. The train model with different suspension layouts is simulated at the speed of $90 \mathrm{~km} / \mathrm{h}$. Acceleration of the train body and displacements of both the body and the primary suspension are discussed.
TABLE 4: The optimal parameter ranges.

\begin{tabular}{lccc}
\hline Parameter & $K(\mathrm{kN} / \mathrm{m})$ & $C(\mathrm{kN} / \mathrm{m} / \mathrm{s})$ & $B(\mathrm{~kg})$ \\
\hline Lower limits & 1500 & 35 & 0 \\
Upper limits & 3300 & 250 & 60000 \\
\hline
\end{tabular}

TABle 5: The optimal parameter of the suspension (only $B$ ).

\begin{tabular}{lcc}
\hline Inerter & Suspension & $B(\mathrm{~kg})$ \\
\hline \multirow{2}{*}{ In parallel } & Primary & 208 \\
& Secondary & 7861 \\
\hline \multirow{2}{*}{ In series } & Primary & 49844 \\
& Secondary & 33168 \\
\hline
\end{tabular}

TABle 6: The optimal parameter of the suspension $(K, C$, and $B)$.

\begin{tabular}{lcccc}
\hline Inerter & Suspension & $K(\mathrm{kN} / \mathrm{m})$ & $C(\mathrm{kN} / \mathrm{m} / \mathrm{s})$ & $B(\mathrm{~kg})$ \\
\hline \multirow{2}{*}{ In parallel } & Primary & 2554.6 & 147.4 & 200 \\
& Secondary & 2415.3 & 131.1 & 34200 \\
\hline \multirow{2}{*}{ In series } & Primary & 3276.3 & 243.3 & 58900 \\
& Secondary & 2519.9 & 170.5 & 32200 \\
\hline
\end{tabular}

In the following figures, the legend needs to explain in advance that, the "tradition" black solid curve represents the traditional layout, the "parallel" red dash curve represents the layout with the optimized inerter in parallel, and the "series" blue dot-dash curve represents the layout with the optimized inerter in series. Furthermore, the "parallel for all" pink dot curve represents the parallel layout with all optimized $K, C$, and $B$ values. And, the last, the "series for all" green thin line with star marks' curve represents the series layout with all optimized $K, C$, and $B$ values.

The accelerations of the train body in all layouts are shown in Figure 4, and all the curves have a good agreement in tendency. Compared with the traditional layout, all four inerter ones contribute an improvement of $8.12 \%$ for "parallel," 8.74\% for "series," 23.26\% for "parallel for all," and $45.68 \%$ for "series for all," respectively, as shown in Table 7 and 8. From Figure 5, PSD of accelerations of the train body shows that all the inerter layouts lower the natural frequency of the train body from $1.6 \mathrm{~Hz}$ to $1.2 \mathrm{~Hz}$. All of them but "series" have lowered the amplitude at the natural frequency as well. We can also see that "parallel for all" introduces more noise in a frequency range around $10-40 \mathrm{~Hz}$.

The displacements of the train body are discussed as well. From Figure 6, the displacements can be seen that, except the curve of "series for all," the other curves are basically the same in the time domain, which can be proven in Tables 7 and 8 that there is almost no improvement, while the curve of "series for all" contributes $13.63 \%$ improvement. In the frequency domain in Figure 7, all curves with the inerter lower the natural frequency but the series curve has its amplitude increased.

For the primary suspension displacement, in Figures 8 and 9, no improvement occurs in both parallel and series curves in the time and frequency domain. On the contrary, cases of "parallel for all" and "series for all" improve the 


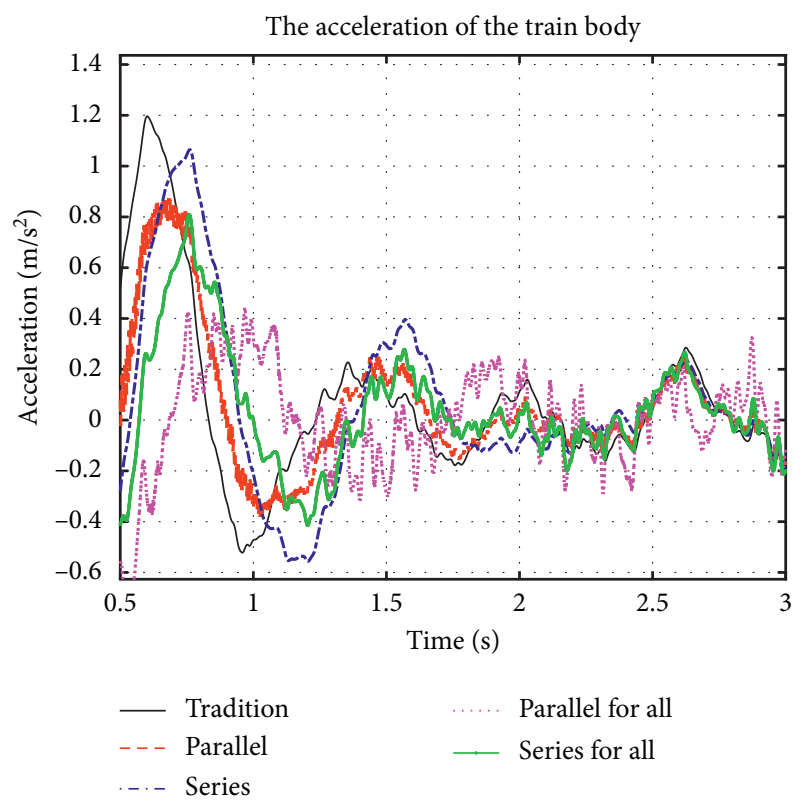

Figure 4: Acceleration of the train body.

TABLE 7: The performance with $B$ optimized.

\begin{tabular}{lccc}
\hline & Vehicle body accelerations $\left(\mathrm{m} / \mathrm{s}^{2}\right)$ & Vehicle body displacement $(\mathrm{m})$ & Primary suspension displacement $(\mathrm{m})$ \\
\hline Tradition & 0.6878 & 0.1265 & 0.0514 \\
Parallel & 0.632 & 0.1264 & 0.0514 \\
Improvement & $8.12 \%$ & 0 & 0 \\
Series & 0.6277 & 0.1276 & 0.0515 \\
Improvement & $8.74 \%$ & $-0.1 \%$ & $-0.3 \%$ \\
\hline
\end{tabular}

Table 8: The performance with $K, C$, and $B$ optimized.

\begin{tabular}{lccc}
\hline & Vehicle body accelerations $\left(\mathrm{m} / \mathrm{s}^{2}\right)$ & Vehicle body displacement $(\mathrm{m})$ & Primary suspension displacement $(\mathrm{m})$ \\
\hline Tradition & 0.6878 & 0.1265 & 0.0514 \\
Parallel for all & 0.5278 & 0.1216 & 0.0429 \\
Improvement & $23.26 \%$ & $3.85 \%$ & $16.58 \%$ \\
Series for all & 0.3737 & 0.1092 & 0.0337 \\
Improvement & $45.68 \%$ & $13.63 \%$ & $34.39 \%$ \\
\hline
\end{tabular}

displacements of the primary suspension by $16.58 \%$ and $34.39 \%$, respectively. The natural frequency is the same as train body displacements that lowered from $1.6 \mathrm{~Hz}$ to $1.2 \mathrm{~Hz}$.

From all the analysis above, we can see that, after the optimization, the inerter layouts do have the benefit for the performance of the train. And, with the optimizing values of all parameters, the layouts show a better improvement than the ones with only inertance optimized. We will investigate the performance of the rail-train coupling system in the next section with these parameters in Table 6.

\section{Performance of the Rail-Train Coupling System}

Performance of the rail-train coupling system is analysed in this section. The rail uses a distance of $175 \mathrm{~m}$, which consists 320 sleepers in total. And, the maximum mode number of the rail selects 160 . The ballast is modelled as the discrete ballast mass as mentioned in section 2 with the shear stiffness and damping counted. And, no overlapping of adjacent ballast masses occurs in this paper. Both the displacement of wheels and rails are considered in this part as equation (4), so the contacting force will be calculated by equation (3). The traveling speed is $90 \mathrm{~km} / \mathrm{h}$ as well. Comparison of the performance between the layouts with the inerter and the traditional layout is analysed as follows.

4.1. Performance of the Train. Performance of the train body is discussed first to check if the benefit with the inerter still holds. In the simulation, a balance procedure is arranged in the beginning, which means to lay the train on the track and make the forces on wheels balance to the weight of the train. So, the performance we are looking through will neglect the balance period and start from $0.5 \mathrm{~s}$. A $2.5 \mathrm{~s}$ period of the curve is analysed in this section. 


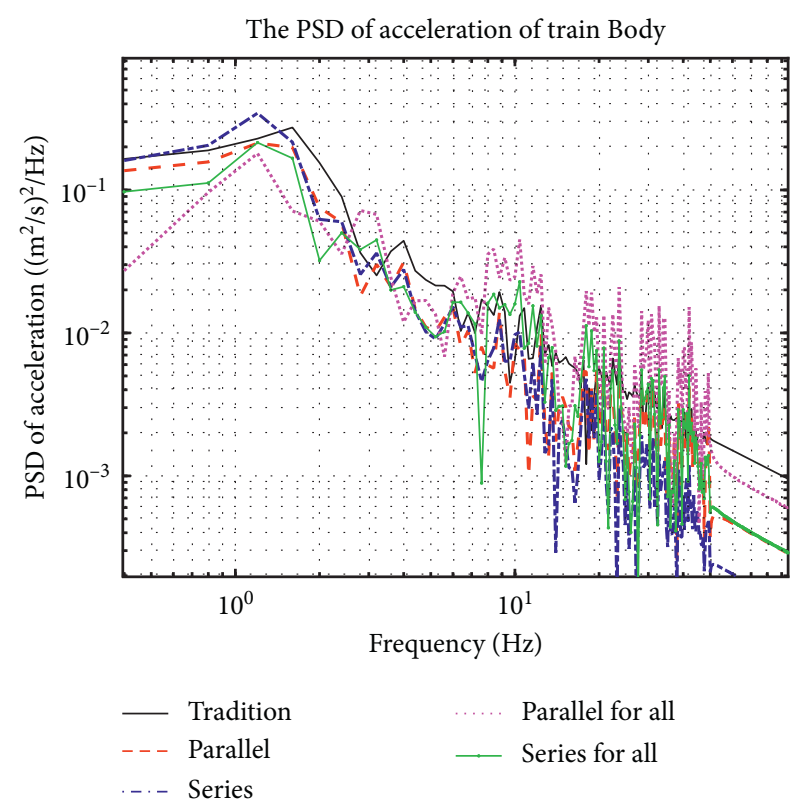

FIGURE 5: PSD of vehicle body acceleration.

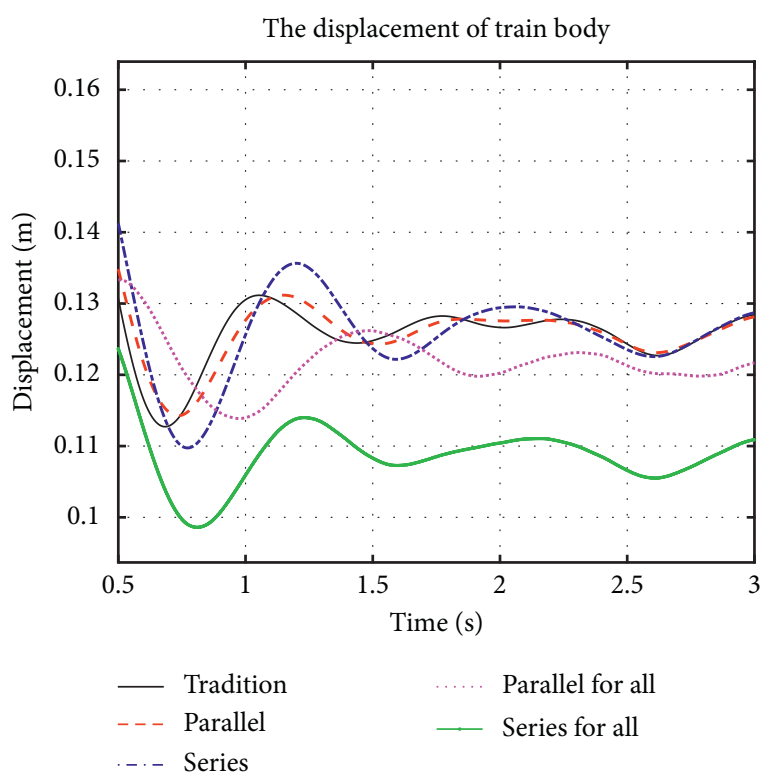

FIGURE 6: Displacement of the vehicle body.

The acceleration of the train body and its PSD are firstly analysed. Figure 10 shows the accelerations of the train body in the time domain. And, from the curves, improvement is still unclear except the max peak location. However, as calculated in Table 9, the RMS value of the acceleration gives a $43.64 \%$ and $30.29 \%$ improvement, respectively. Furthermore, lots of noise can be found in the curve of parallel compared with the others in Figure 10. It can be explained by Figure 11, which shows PSD of train body acceleration. In Figure 11, the inerters in both parallel and series layouts show an influence that the natural frequency of the acceleration has been lowered both in amplitude and frequency. The natural frequency changes from $1.6 \mathrm{~Hz}$ to $1.2 \mathrm{~Hz}$, which

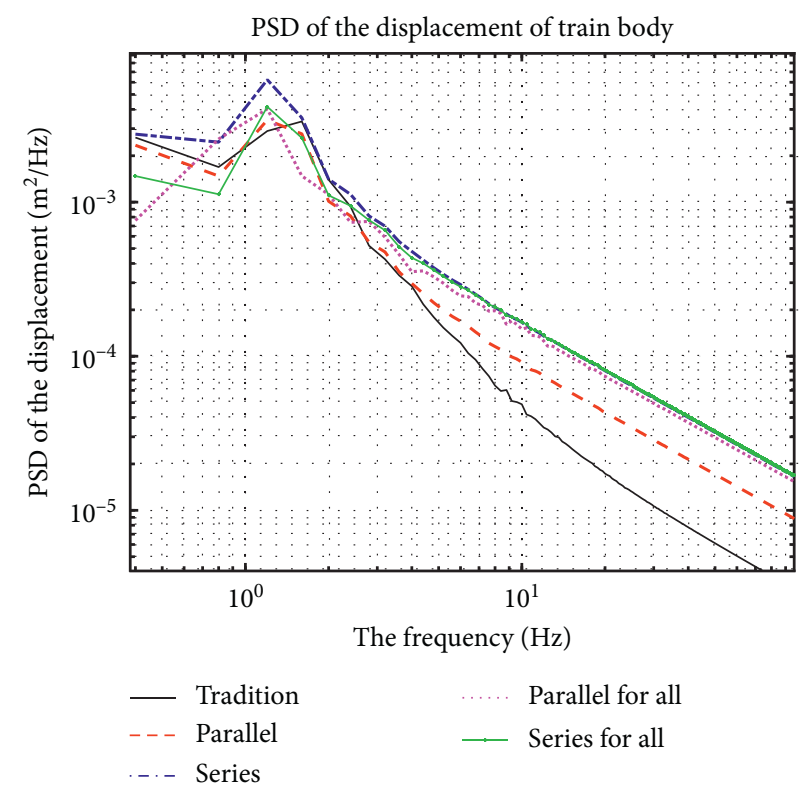

Figure 7: PSD of vehicle body displacement.

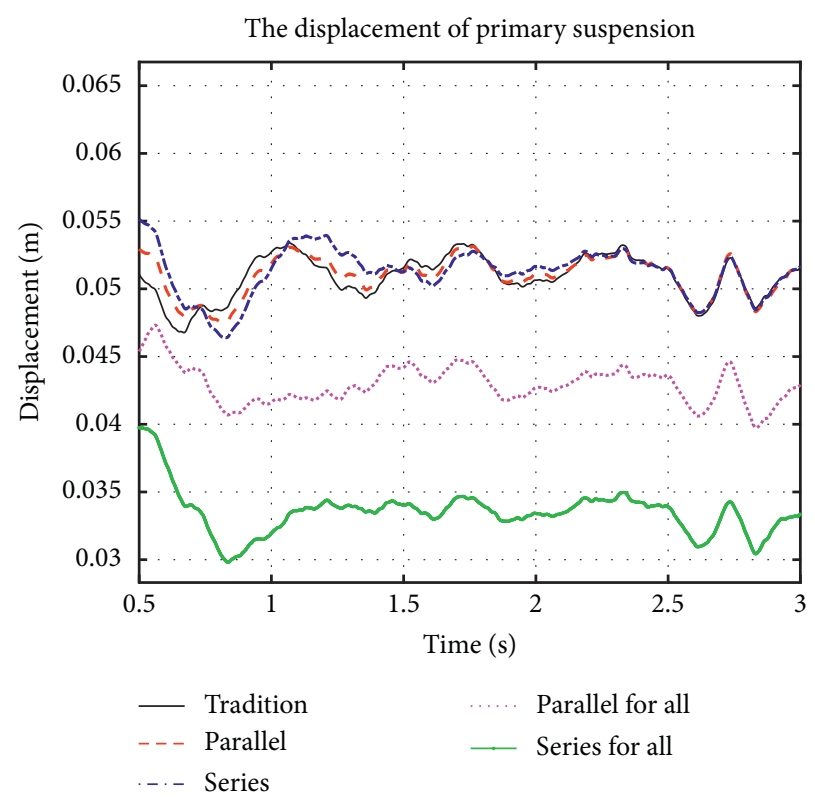

Figure 8: Primary suspension displacement.

is the same as Section 3.2, and the amplitude lowered from 0.3448 to 0.1967 and $0.2795\left(\mathrm{~m} / \mathrm{s}^{2}\right)^{2} / \mathrm{Hz}$. However, the isolation for higher frequencies, which is in the range of $10-40 \mathrm{~Hz}$, is weakened by using the inerter, especially in the parallel layout.

The pitch of the train body is also considered in Figures 12 and 13. Compared to the traditional layout, the natural frequency of pitch is lowered form $2.4 \mathrm{~Hz}$ to $0.8 \mathrm{~Hz}$. However, pitch accelerations of the layouts with the inerter suffer influence of the high frequencies as well. The RMS value of the parallel layout worsens $9.73 \%$ because of the introduction of the high frequencies, while the RMS value of the series layout improves to $15.84 \%$. 




FIgURE 9: PSD of suspension displacement.

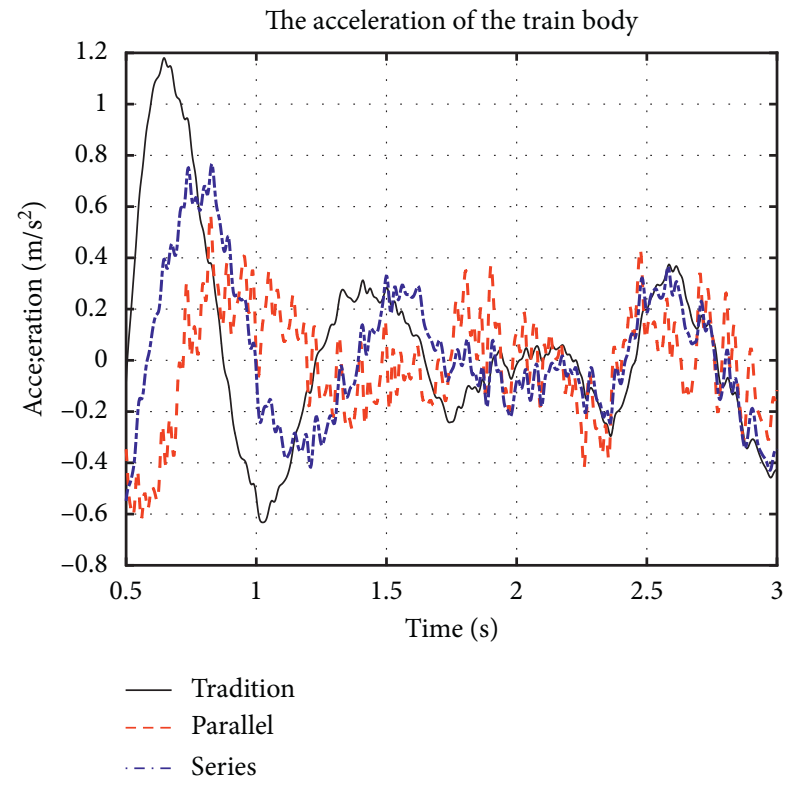

FIgURE 10: Acceleration of the train body.

TABLE 9: The performance of the rail-train coupling system.

\begin{tabular}{|c|c|c|c|c|c|}
\hline Acceleration & Vehicle body $\left(\mathrm{m} / \mathrm{s}^{2}\right)$ & Vehicle pitch $\left(\mathrm{rad} / \mathrm{s}^{2}\right)$ & Rail $\left(\mathrm{m} / \mathrm{s}^{2}\right)$ & Sleeper $\left(\mathrm{m} / \mathrm{s}^{2}\right)$ & Ballast $\left(\mathrm{m} / \mathrm{s}^{2}\right)$ \\
\hline Tradition & 0.3841 & 0.0196 & 0.6176 & 0.8573 & 0.5934 \\
\hline Parallel & 0.2165 & 0.0215 & 0.6214 & 0.7469 & 0.5046 \\
\hline Improvement & $43.64 \%$ & $-9.73 \%$ & $-0.6 \%$ & $12.88 \%$ & $14.96 \%$ \\
\hline Series & 0.2678 & 0.0165 & 0.5794 & 0.6839 & 0.4608 \\
\hline Improvement & $30.29 \%$ & $15.84 \%$ & $6.19 \%$ & $20.24 \%$ & $22.35 \%$ \\
\hline
\end{tabular}

From the acceleration of the train body, we can see that either the train model only or the rail-train coupling system can be improved by the introduction of inerters. However, the pitch acceleration suffers more noise when the inerter is connected in parallel, so the combination of inerters matters and the optimization needs to be thorough. 


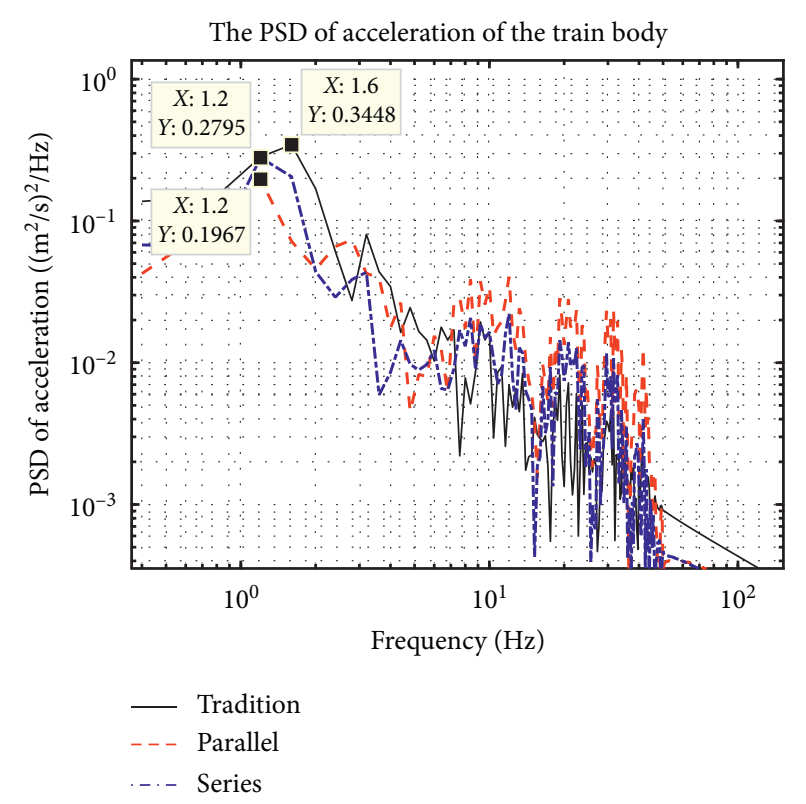

FIgURE 11: PSD of train body acceleration.

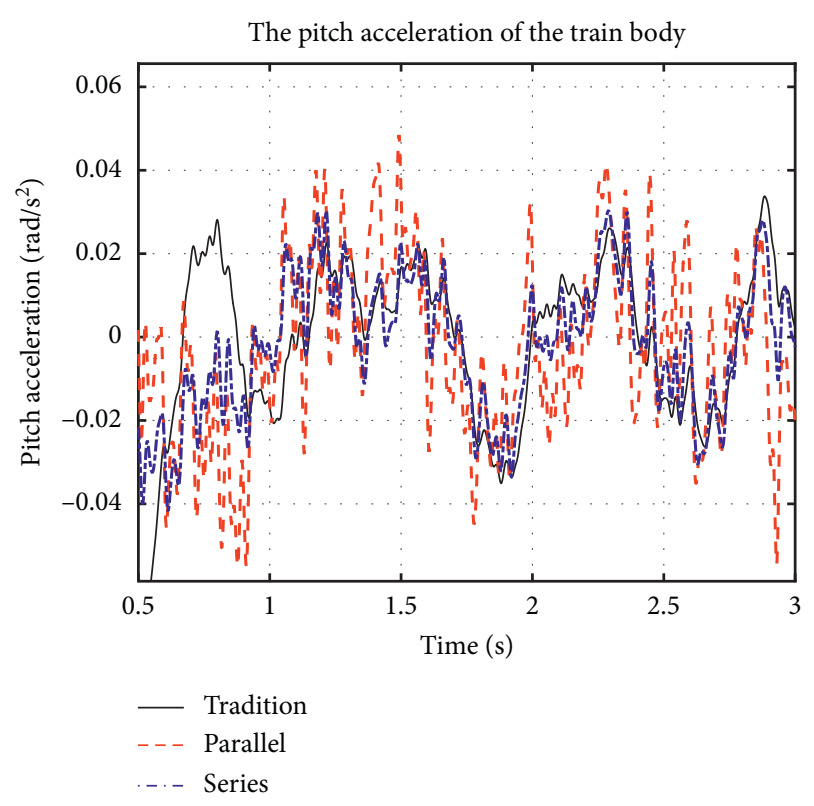

FIGURE 12: Pitch acceleration of train body.

4.2. Performance of the Rail System. In this section, performance of the rail system is analysed. The location $1 / 2 \mathrm{~L}$ is selected in the middle of the whole distance, at which all the rail, sleeper, and ballast are discussed.

Figure 14 shows the acceleration of the rail at $1 / 2 \mathrm{~L}$ in the time domain. In Figure 14(a), the time window is the same as train analysis when the whole train runs over the middle location of the rail. Two severe vibration periods happen in the time line which indicates that the front and rear bogies run over the location. The max acceleration of the rail in $1 / 2 \mathrm{~L}$ is around $3-4 \mathrm{~m} / \mathrm{s}^{2}$. In Figure 14(b), a zoomed figure of Figure 14(a) is shown, which reflects the acceleration of the rail when the front bogie runs over, and it can be seen more

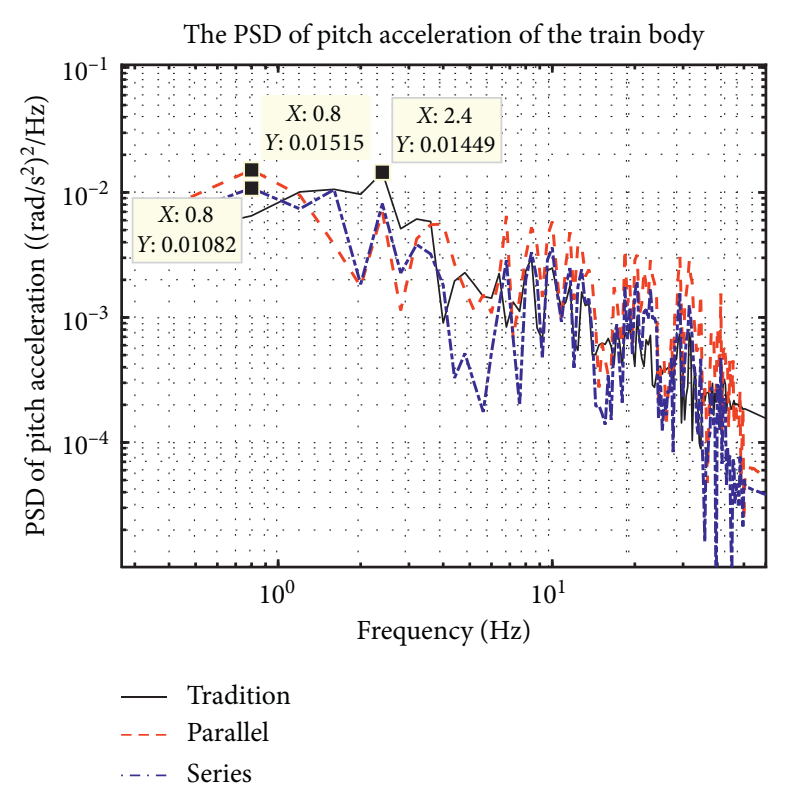

FIGURE 13: PSD of pitch acceleration.

in detail that both layouts with the inerter have a good agreement in tendency with the traditional one. However, the series one shows better vibration attenuation than the parallel one in some peaks. The RMS values prove the performances of the figure also shown in Table 9. For the parallel layout, $0.6 \%$ deterioration happens compared with the traditional one, which is so small that can be neglected. On the contrary, the series one gives a $6.19 \%$ improvement in the RMS value of the acceleration.

In the frequency domain, curves in Figure 15(a) are the PSD of all three layouts. The series one has a lower PSD curve during $0-10 \mathrm{~Hz}$. The natural frequencies of the three curves are the same at $41.6 \mathrm{~Hz}$ in Figure 15(b). However, both inerter layouts show a lower amplitude of the PSD in natural frequency, and the series one gives much more attenuation about $22.2 \%$.

Figure 16 shows the performance of the middle sleeper. From Figure 16(a), max acceleration is around $4 \mathrm{~m} / \mathrm{s}^{2}$. Figure 16(b) shows details that both layouts with the inerter attenuate the vibration of the sleeper, and the series one does better. RMS values of the sleeper acceleration in Table 9 show the improvement of $12.88 \%$ and $20.24 \%$, respectively, compared with the traditional layout.

And, in the frequency domain in Figure 17, same as the PSD of the rail, all the layouts give the similar tendency of the curves. The natural frequency is $41.6 \mathrm{~Hz}$ as well, and inerter layouts lower the amplitude of the PSD. For the parallel layout, the attenuation is $21.45 \%$, and for the series one, the number is $31.91 \%$. However, around $20 \mathrm{~Hz}$, both the layouts with inerters show the deterioration compared to the traditional layout.

The vibration of ballast is a very important index for the ballast track. The running safety and serve period of the track system are all affected by its performance. We can see from Figures 18(a) and 18(b) that the max amplitude of the ballast is less than $3 \mathrm{~m} / \mathrm{s}^{2}$, and the layouts with the inerter attenuate 


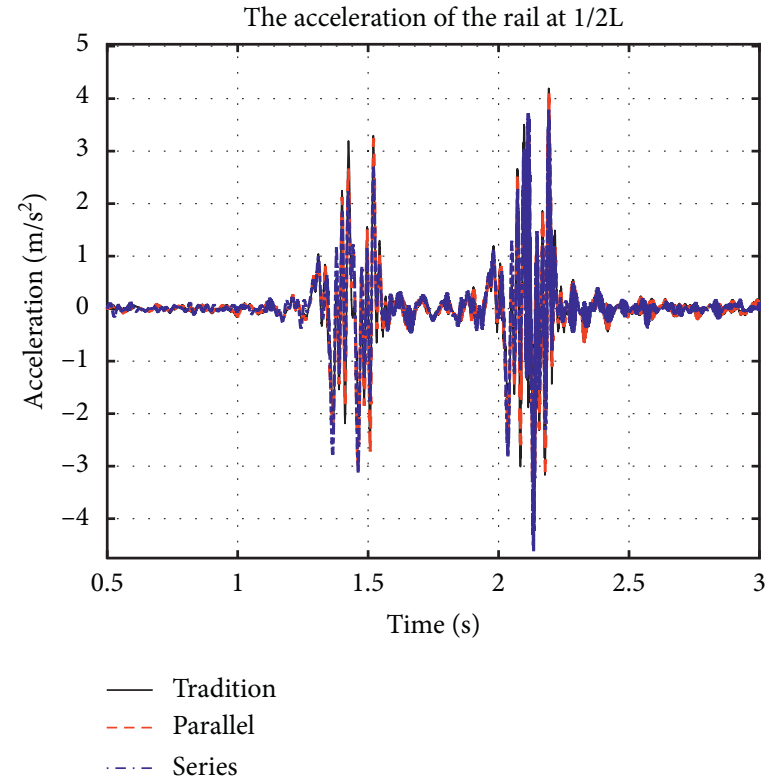

(a)

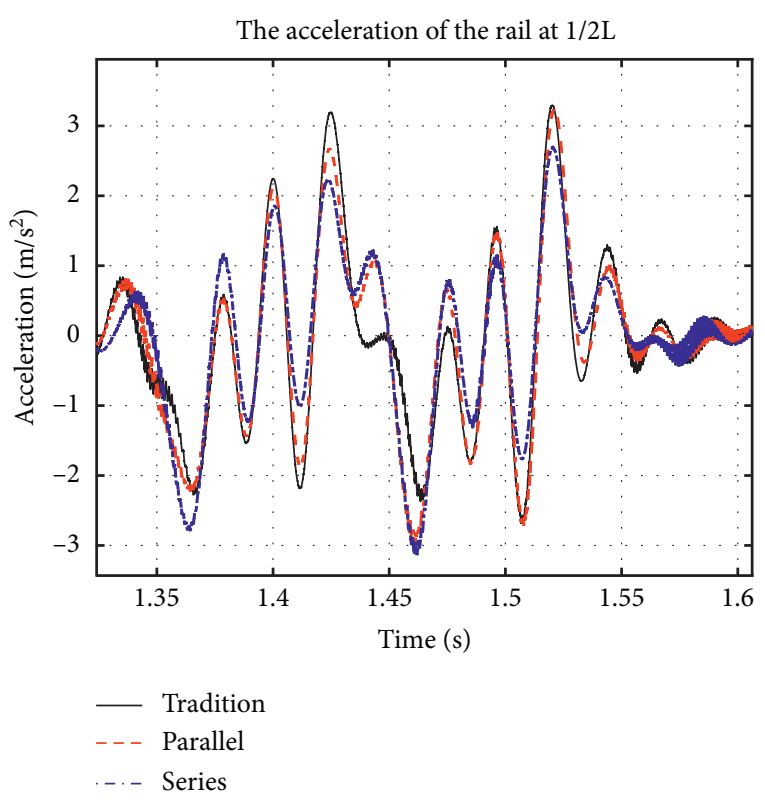

(b)

FIgURE 14: Acceleration of the rail at 1/2L. (a) The whole train runs over. (b) The front bogie runs over.

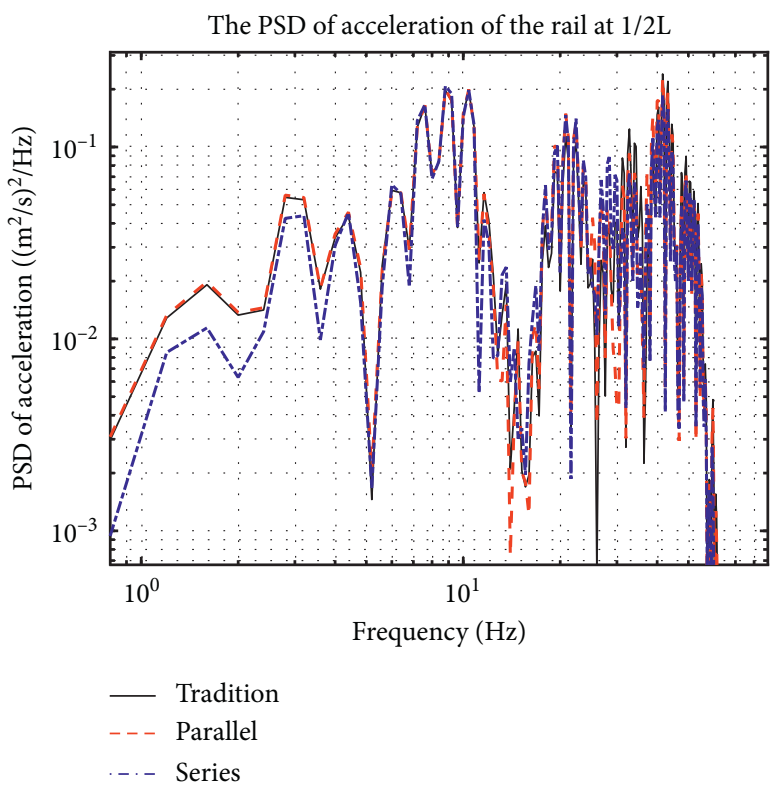

(a)

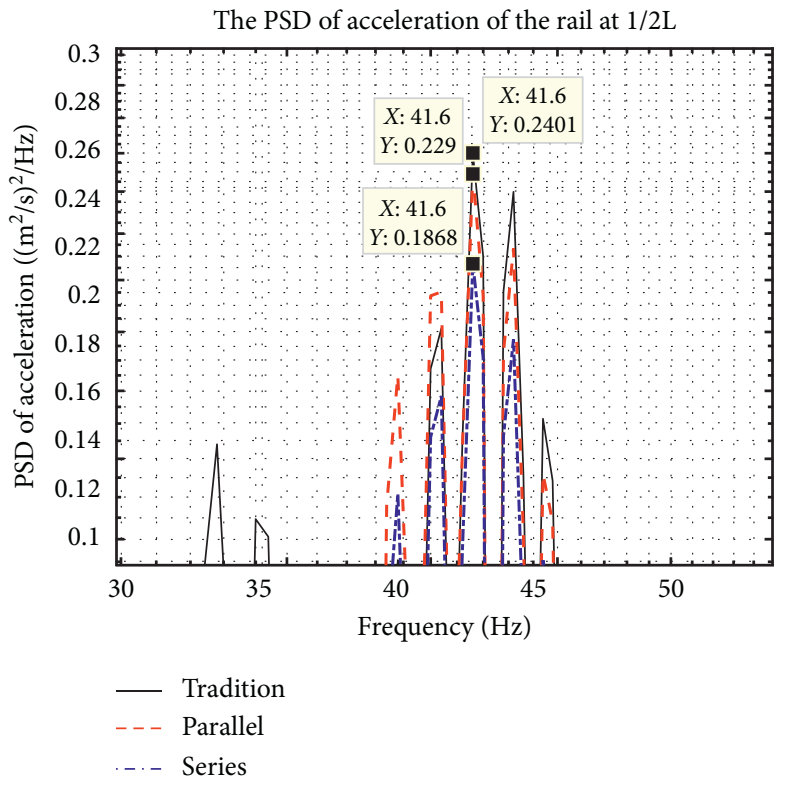

(b)

Figure 15: PSD of pitch acceleration. (a) Range of $0-100 \mathrm{~Hz}$. (b) Peaks at natural frequency.

the vibration of the ballast. The improvement of the RMS value is $14.96 \%$ and $22.35 \%$ for parallel and series layouts, respectively. In the frequency domain in Figure 19, the natural frequencies are the same as the rail and sleeper, which is $41.6 \mathrm{~Hz}$. And, the drop of the amplitude is $22.28 \%$ and $32.5 \%$ for parallel and series layouts. The deterioration exists around $20 \mathrm{~Hz}$ as well.
After evaluating both the performances of the train and rail system, both layouts with the inerter can benefit from the dynamic response in some level. And, we can find that the series layout is better than the parallel one. Inerters can attenuate vibration well when its natural frequency is under $10 \mathrm{~Hz}$, while more vibration is introduced in a range of $10-40 \mathrm{~Hz}$. 


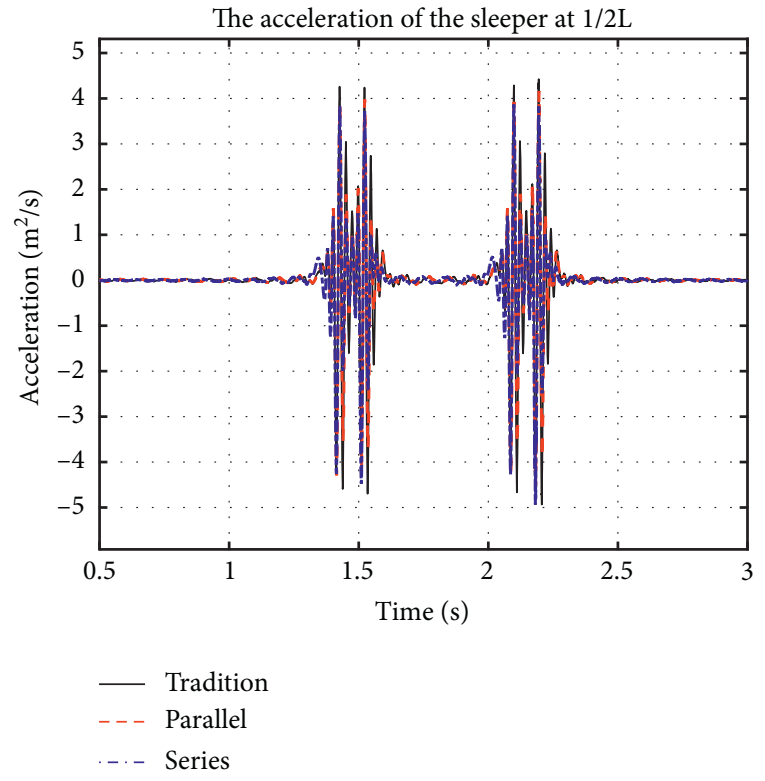

(a)

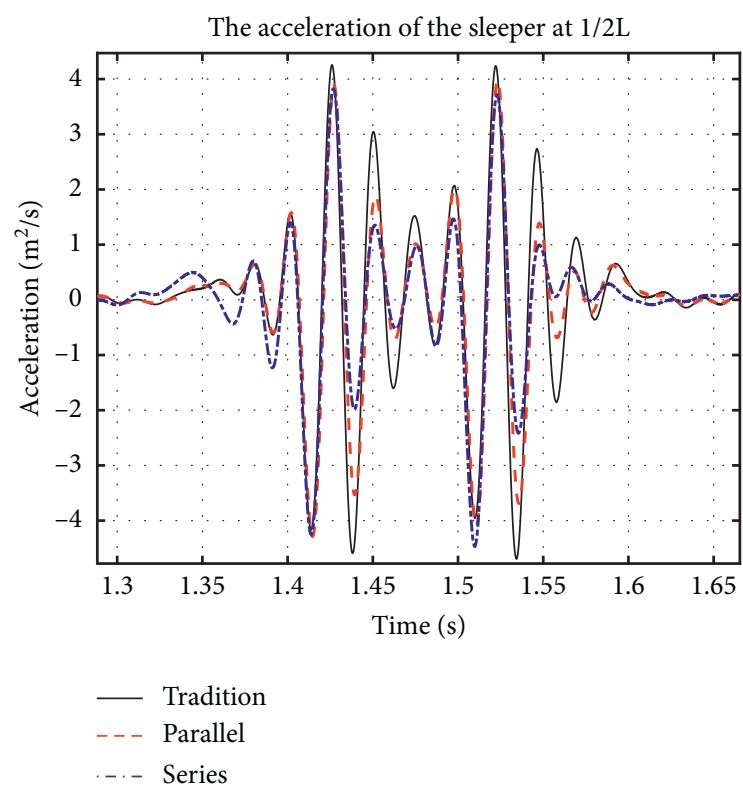

(b)

Figure 16: Acceleration of the sleeper at 1/2L. (a) The whole train runs over. (b) The front bogie runs over.

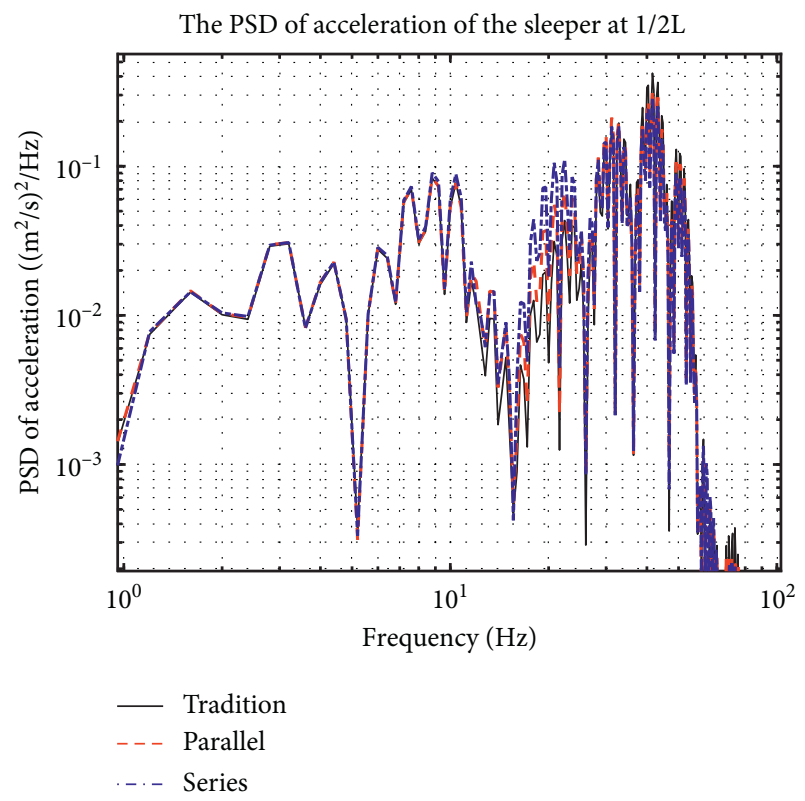

(a)

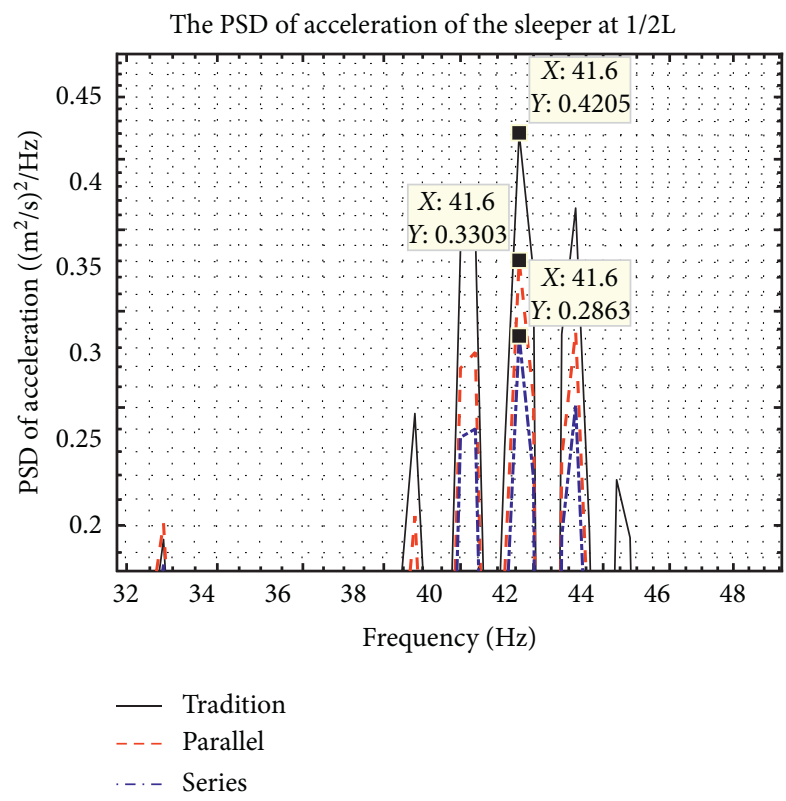

(b)

Figure 17: PSD of sleeper acceleration. (a) Range of 0-100 Hz. (b) Peaks at natural frequency. 


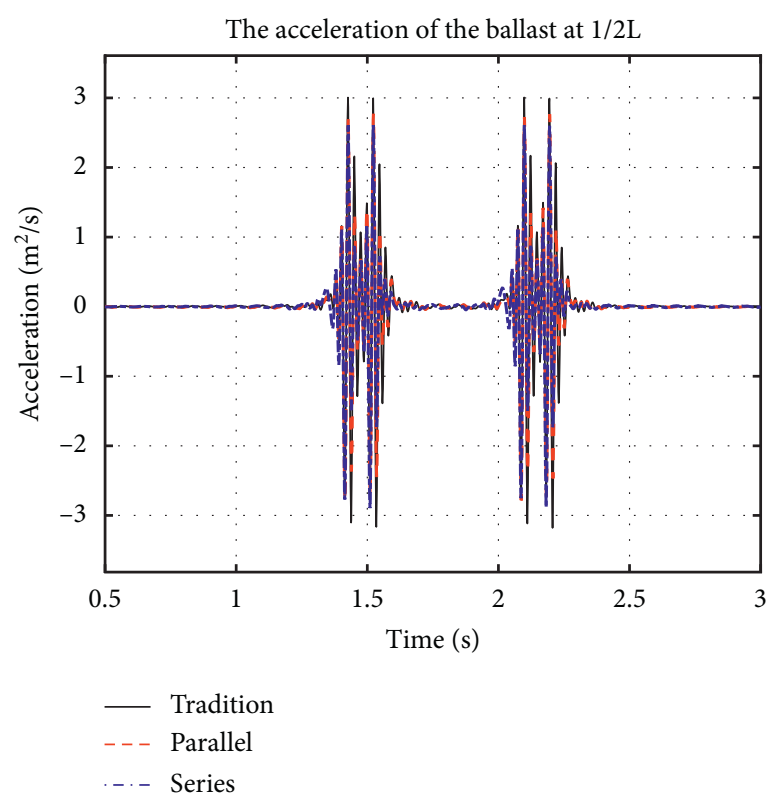

(a)

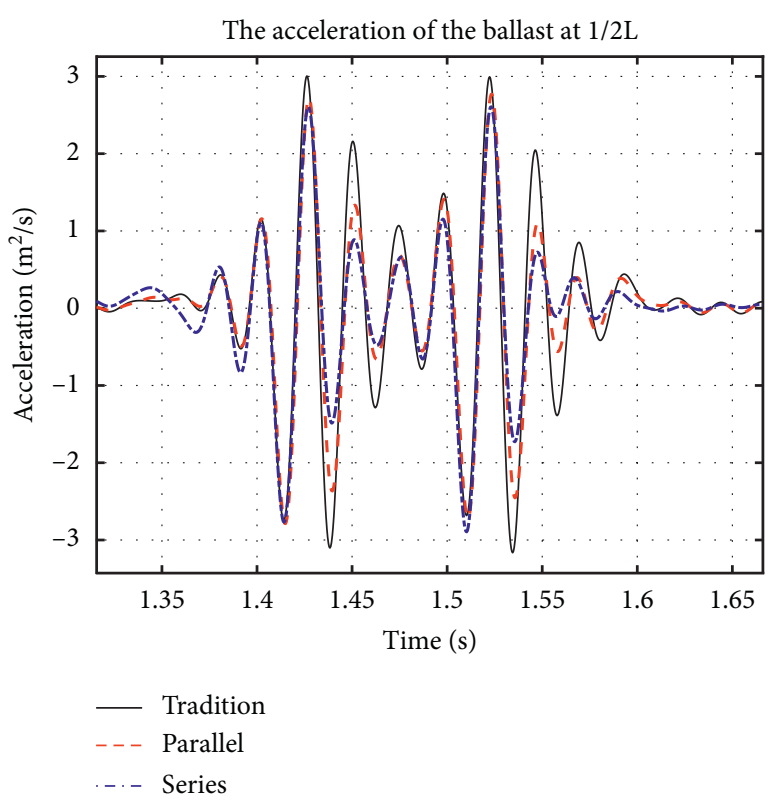

(b)

Figure 18: Acceleration of the ballast at 1/2L. (a) The whole train runs over. (b) The front bogie runs over.

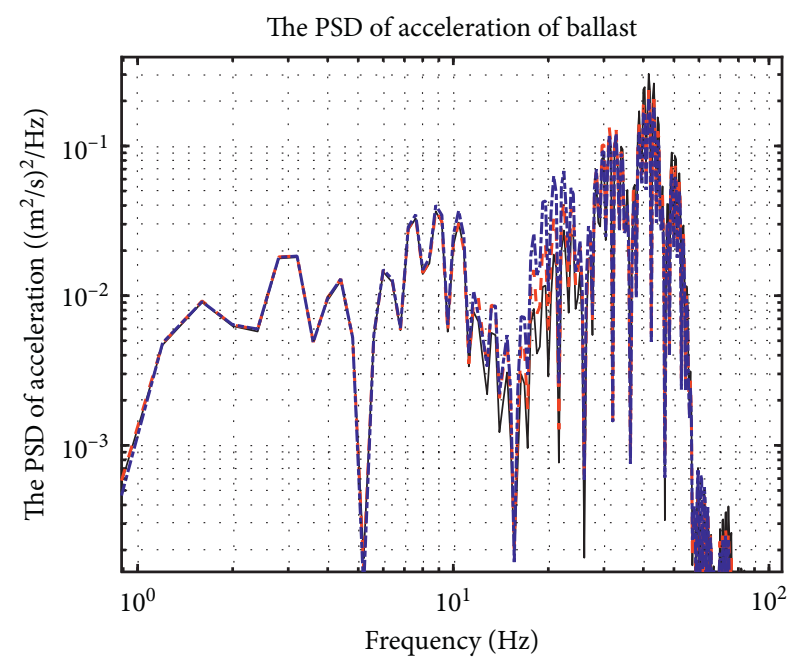

(a)

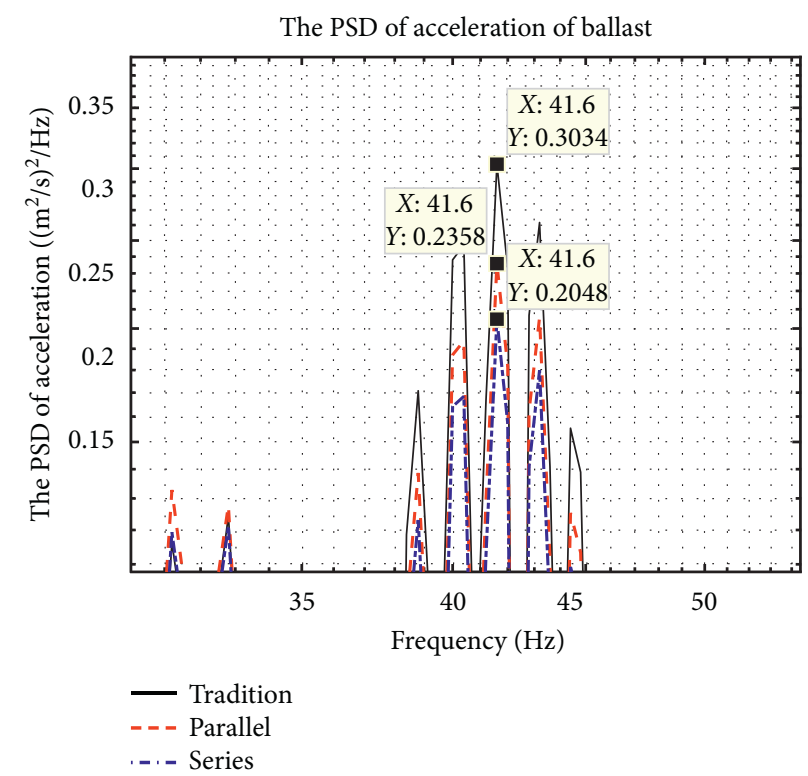

(b)

FIgURE 19: PSD of ballast acceleration. (a) Range of $0-100 \mathrm{~Hz}$. (b) Peaks at natural frequency. 


\section{Conclusions}

In this paper, vertical vibration performance of a rail-train coupling system is optimized and analysed with the introduction of inerters for both primary and secondary suspensions. The influence of the inerter for both the train and the rail system is discussed. The following conclusions can be drawn based on the obtained results.

(1) The inerter can be of benefit to both the typical Chinese passenger train and the traditional rail system with sleepers and ballast in their coupling system. $30.29 \%$ and $15.84 \%$ improvements are given in the train body acceleration and its pitch acceleration by the series layout. And, for the rail system, $6.19 \%, 20.24 \%$, and $22.35 \%$ improvements are shown for the rail, sleeper, and ballast, respectively. This is of significant meaning for a ballast rail system. Serving period and maintaining consumption will be improved.

(2) The parallel and series connection layouts with the inerter are introduced and optimized by PSO. In the simulation of this study, the series layout shows a better performance in either amplitude attenuation or high frequency block aspects. The parallel layout gives a deterioration in the pitch acceleration of the train body.

(3) In this paper, inerters in both parallel and series layouts can attenuate vibration well in the range of $0-10 \mathrm{~Hz}$, and the natural frequency of the train model lowered because of inerters. However, more noise is introduced in a range of $10-40 \mathrm{~Hz}$ for the train and around $20 \mathrm{~Hz}$ for the rail.

Two basic combinations of the inerters are discussed in this paper; for the future work, more complex but practical combination can be explored for better performance of the rail-train coupling system.

\section{Appendix}

\section{Equations of the rail and train system with inerters:}

Rail:

$$
\begin{aligned}
\ddot{q}_{k}(t) & +\sum_{i=1}^{N} C_{p i} Y_{k}\left(x_{i}\right) \sum_{h=1}^{M N} Y_{h}\left(x_{i}\right) \dot{q}_{h}(t)+\frac{E I}{m_{r}}\left(\frac{k \pi}{l}\right)^{4} q_{k}(t)+\sum_{i=1}^{N} K_{p i} Y_{k}\left(x_{i}\right) \sum_{h=1}^{M N} Y_{h}\left(x_{i}\right) q_{h}(t)-\sum_{i=1}^{N} C_{p i} Y_{k}\left(x_{i}\right) \dot{Z}_{s i}(t) \\
& -\sum_{i=1}^{N} K_{p i} Y_{k}\left(x_{i}\right) Z_{s i}(t)=\sum_{j=1}^{4} p_{j}(t) Y_{k}\left(x_{w j}\right), \quad(k=1 \sim \mathrm{NM}) .
\end{aligned}
$$

Sleeper:

$$
\begin{aligned}
M_{s i} \ddot{Z}_{s i}(t) & +\left(C_{p i}+C_{b i}\right) \dot{Z}_{s i}(t)+\left(K_{p i}+K_{b i}\right) Z_{s i}(t)-C_{b i} \dot{Z}_{b i}(t)-K_{b i} Z_{b i}(t)-C_{p i} \sum_{h=1}^{M N} Y_{h}\left(x_{i}\right) \dot{q}_{h}(t) \\
& -K_{p i} \sum_{h=1}^{M N} Y_{h}\left(x_{i}\right) q_{h}(t)=0, \quad(i=1 \sim N) .
\end{aligned}
$$

Ballast:

$$
\begin{aligned}
M_{b i} \ddot{Z}_{b i}(t) & +\left(C_{b i}+C_{f i}+2 C_{w i}\right) \dot{Z}_{b i}(t)+\left(K_{b i}+K_{f i}+2 K_{w i}\right) Z_{b i}(t)-C_{b i} \dot{Z}_{s i}(t)-K_{b i} Z_{s i}(t)-C_{w i} \dot{Z}_{b(i+1)}(t)-K_{w i} Z_{b(i+1)}(t) \\
& -C_{w i} \dot{Z}_{b(i-1)}(t)-K_{w i} Z_{b(i-1)}(t)=0, \quad(i=1 \sim N) .
\end{aligned}
$$

Train: 
(1) 10 degrees of freedom with parallel connected inerters.
Body:

$$
\begin{array}{r}
m_{c} \ddot{z}_{c}+2 B_{s z} \ddot{z}_{c}+2 C_{s z} \dot{z}_{c}+2 K_{s z} z_{c}-B_{s z} \ddot{z}_{t 1}-B_{s z} \ddot{z}_{t 2}-C_{s z} \dot{z}_{t 1}-C_{s z} \dot{z}_{t 2}-K_{s z} z_{t 1}-K_{s z} z_{t 2}=m_{c} g \\
J_{c} \ddot{\beta}_{c}+2 B_{s z} l_{c}^{2} \ddot{\beta}_{c}+2 C_{s z} l_{c}^{2} \dot{\beta}_{c}+2 K_{s z} l_{c}^{2} \beta_{c}+B_{s z} l_{c} \ddot{z}_{t 1}-B_{s z} l_{c} \ddot{z}_{t 2}+C_{s z} l_{c} \dot{z}_{t 1}-C_{s z} l_{c} \dot{z}_{t 2}+K_{s z} l_{c} z_{t 1}-K_{s z} l_{c} z_{t 2}=0 .
\end{array}
$$

Bogies:

$$
\begin{aligned}
& m_{t} \ddot{z}_{t 1}+\left(2 B_{p z}+B_{s z}\right) \ddot{z}_{t 1}+\left(2 C_{p z}+C_{s z}\right) \dot{z}_{t 1}+\left(2 K_{p z}+K_{s z}\right) z_{t 1}-B_{s z} \ddot{z}_{c}-B_{p z} \ddot{z}_{w 1}-B_{p z} \ddot{z}_{w 2} \\
&-C_{s z} \dot{z}_{c}-C_{p z} \dot{z}_{w 1}-C_{p z} \dot{z}_{w 2}-K_{s z} z_{c}-K_{p z} z_{w 1}-K_{p z} z_{w 2}+B_{s z} l_{c} \ddot{\beta}_{c}+C_{s z} l_{c} \dot{\beta}_{c}+K_{s z} l_{c} \beta_{c}=m_{t} g, \\
& J_{t} \ddot{\beta}_{t 1}+2 B_{p z} l_{t}^{2} \ddot{\beta}_{t 1}+2 C_{p z} l_{t}^{2} \dot{\beta}_{t 1}+2 K_{p z} l_{t}^{2} \beta_{t 1}+B_{p z} l_{t} \ddot{z}_{w 1}-B_{p z} \ddot{z}_{t 2}+C_{p z} l_{t} \dot{z}_{w 1}-C_{p z} l_{t} \dot{z}_{w 2}+K_{p z} l_{t} z_{w 1}-K_{p z} l_{t} z_{w 2}=0, \\
& m_{t} \ddot{z}_{t 2}+\left(2 B_{p z}+B_{s z}\right) \ddot{z}_{t 2}+\left(2 C_{p z}+C_{s z}\right) \dot{z}_{t 2}+\left(2 K_{p z}+K_{s z}\right) z_{t 2}-B_{s z} \ddot{z}_{c}-B_{p z} \ddot{z}_{w 3}-B_{p z} \ddot{z}_{w 4} \\
& \quad-C_{s z} \dot{z}_{c}-C_{p z} \dot{z}_{w 3}-C_{p z} \dot{z}_{w 4}-K_{s z} z_{c}-K_{p z} z_{w 3}-K_{p z} z_{w 4}-B_{s z} l_{c} \ddot{\beta}_{c}-C_{s z} l_{c} \dot{\beta}_{c}-K_{s z} l_{c} \beta_{c}=m_{t} g, \\
& \ddot{J}_{t}+2 B_{z} l_{t}^{2} \ddot{\beta}_{t 2}+2 C_{p z} l_{t}^{2} \dot{\beta}_{t 2}+2 K_{p z} l_{t}^{2} \beta_{t 2}+B_{p z} l_{t} \ddot{z}_{w 3}-B_{p z} l_{t} \ddot{z}_{w 4}+C_{p z} l_{t} \dot{z}_{w 3}-C_{p z} l_{t} \dot{z}_{w 4}+K_{p z} l_{t} z_{w 3}-K_{p z} l_{t} z_{w 4}=0 .
\end{aligned}
$$

Wheelsets:

$$
\begin{aligned}
& m_{w} \ddot{z}_{w 1}+B_{p z} \ddot{z}_{w 1}+C_{p z} \dot{z}_{w 1}+K_{p z} z_{w 1}-B_{p z} \ddot{z}_{t 1}-C_{p z} \dot{z}_{t 1}-K_{p z} z_{t 1}+B_{p z} l_{t} \ddot{\beta}_{t 1}+C_{p z} l_{t} \dot{\beta}_{t 1}+K_{p z} l_{t} \beta_{t 1}=m_{w} g-P_{1}, \\
& m_{w} \ddot{z}_{w 2}+B_{p z} \ddot{z}_{w 2}+C_{p z} \dot{z}_{w 2}+K_{p z} z_{w 2}-B_{p z} \ddot{z}_{t 1}-C_{p z} \dot{z}_{t 1}-K_{p z} z_{t 1}-B_{p z} l_{t} \ddot{\beta}_{t 1}-C_{p z} l_{t} \dot{\beta}_{t 1}-K_{p z} l_{t} \beta_{t 1}=m_{w} g-P_{2}, \\
& m_{w} \ddot{z}_{w 3}+B_{p z} \ddot{z}_{w 3}+C_{p z} \dot{z}_{w 3}+K_{p z} z_{w 3}-B_{p z} \ddot{z}_{t 2}-C_{p z} \dot{z}_{t 2}-K_{p z} z_{t 2}+B_{p z} l_{t} \ddot{\beta}_{t 2}+C_{p z} \dot{\beta}_{t}+K_{t 2} l_{t} \beta_{t 2}=m_{w} g-P_{3}, \\
& m_{w} \ddot{z}_{w 4}+B_{z} \ddot{z}_{w 4}+C_{p z} \dot{z}_{w 4}+K_{p z} z_{w 4}-B_{p z} \ddot{z}_{t 2}-C_{p z} \dot{z}_{t 2}-K_{p z} z_{t 2}-B_{p z} l_{t} \ddot{\beta}_{t 2}-C_{p z} l_{t} \dot{\beta}_{t 2}-K_{p z} l_{t} \beta_{t 2}=m_{w} g-P_{4} .
\end{aligned}
$$

(2) 16 degrees of freedom with the inerter connected in series with the damper.

Body:

$$
\begin{array}{r}
m_{c} \ddot{z}_{c}+2 B_{s z} \ddot{z}_{c}+2 K_{s z} z_{c}-B_{s z} \ddot{z}_{s 1}-B_{s z} \ddot{z}_{s 2}-K_{s z} z_{t 1}-K_{s z} z_{t 2}=m_{c} g, \\
J_{c} \ddot{\beta}_{c}+2 B_{s z} l_{c}^{2} \ddot{\beta}_{c}+2 K_{s z} l_{c}^{2} \beta_{c}+B_{s z} l_{c} \ddot{z}_{s 1}-B_{s z} l_{c} \ddot{z}_{s 2}+K_{s z} l_{c} z_{t 1}-K_{s z} l_{c} z_{t 2}=0 .
\end{array}
$$

Bogies:

$$
\begin{array}{r}
m_{t} \ddot{z}_{t 1}+2 B_{p z} \ddot{z}_{t 1}+\left(2 K_{p z}+K_{s z}\right) z_{t 1}-B_{p z} \ddot{z}_{z 1}-B_{p z} \ddot{z}_{z 2}-C_{s z} \dot{z}_{s 1}+C_{p z} \dot{z}_{t 1}-K_{s z} z_{c}-K_{p z} z_{w 1}-K_{p z} z_{w 2}+K_{s z} l_{c} \beta_{c}=m_{t} g, \\
\ddot{\beta}_{t 1}+2 B_{p z} l_{t}^{2} \ddot{\beta}_{t 1}+2 K_{p z} l_{t}^{2} \beta_{t 1}+B_{p z} l_{t} \ddot{z}_{z 1}-B_{p z} l_{t} \ddot{z}_{z 2}+K_{p z} l_{t} z_{w 1}-K_{p z} l_{t} z_{w 2}=0, \\
m_{t} \ddot{z}_{t 2}+2 B_{p z} \ddot{z}_{t 2}+\left(2 K_{p z}+K_{s z}\right) z_{t 2}-B_{p z} \ddot{z}_{z 3}-B_{p z} \ddot{z}_{z 4}-C_{s z} \dot{z}_{s 2}+C_{p z} \dot{z}_{t 2}-K_{s z} z_{c}-K_{p z} z_{w 3}-K_{p z} z_{w 4}-K_{s z} l_{c} \beta_{c}=m_{t} g, \\
\ddot{\beta}_{t}+2 B_{p z} l_{t}^{2} \ddot{\beta}_{t 2}+2 K_{p z} l_{t}^{2} \beta_{t 2}+B_{p z} l_{t} \ddot{z}_{z 3}-B_{p z} l_{t} \ddot{z}_{z 4}+K_{p z} l_{t} z_{w 3}-K_{p z} l_{t} z_{w 4}=0 .
\end{array}
$$


Wheelsets:

$$
\begin{aligned}
& m_{w} \ddot{z}_{w 1}+C_{p z} \dot{z}_{w 1}+K_{p z} z_{w 1}-C_{p z} \dot{z}_{z 1}-K_{p z} z_{t 1}+K_{p z} l_{t} \beta_{t 1}=m_{w} g-P_{1}, \\
& m_{w} \ddot{z}_{w 2}+C_{p z} \dot{z}_{w 2}+K_{p z} z_{w 2}-C_{p z} \dot{z}_{z 2}-K_{p z} z_{t 1}-K_{p z} l_{t} \beta_{t 1}=m_{w} g-P_{2}, \\
& m_{w} \ddot{z}_{w 3}+C_{p z} \dot{z}_{w 3}+K_{p z} z_{w 3}-C_{p z} \dot{z}_{z 3}-K_{p z} z_{t 2}+K_{p z} l_{t} \beta_{t 2}=m_{w} g-P_{3}, \\
& m_{w} \ddot{z}_{w 4}+C_{p z} \dot{z}_{w 4}+K_{p z} z_{w 4}-C_{p z} \dot{z}_{z 4}-K_{p z} z_{t 2}-K_{p z} l_{t} \beta_{t 2}=m_{w} g-P_{4} .
\end{aligned}
$$

Extra freedom between the damper and inerter in the suspension $\left(Z_{s i}\right.$ represents the extra freedom between the damper and inerter in the $i^{\text {th }}$ secondary suspension; and, $Z_{z i}$ represents the extra freedom between the damper and inerter in the $j^{\text {th }}$ primary suspension):

$$
\begin{array}{r}
B_{s z} \ddot{z}_{s 1}-B_{s z} \ddot{z}_{c}+B_{s z} l_{c} \ddot{\beta}_{c}+C_{s z} \dot{z}_{s 1}-C_{s z} \dot{z}_{t 1}=0, \\
B_{s z} \ddot{z}_{s 2}-B_{s z} \ddot{z}_{c}-B_{s z} l_{c} \ddot{\beta}_{c}+C_{s z} \dot{z}_{s 2}-C_{s z} \dot{z}_{t 2}=0, \\
B_{p z} \ddot{z}_{z 1}-B_{p z} \ddot{z}_{t 1}+B_{p z} l_{t} \ddot{\beta}_{t 1}+C_{p z} \dot{z}_{z 1}-C_{p z} \dot{z}_{w 1}=0, \\
B_{p z} \ddot{z}_{z 2}-B_{p z} \ddot{z}_{t 1}-B_{p z} l_{t} \ddot{\beta}_{t 1}+C_{p z} \dot{z}_{z 2}-C_{p z} \dot{z}_{w 2}=0, \\
B_{p z} \ddot{z}_{z 3}-B_{p z} \ddot{z}_{t 2}+B_{p z} l_{t} \ddot{\beta}_{t 2}+C_{p z} \dot{z}_{z 3}-C_{p z} \dot{z}_{w 3}=0, \\
B_{p z} \ddot{z}_{z 4}-B_{p z} \ddot{z}_{t 2}-B_{p z} l_{t} \ddot{\beta}_{t 2}+C_{p z} \dot{z}_{z 4}-C_{p z} \dot{z}_{w 4}=0 .
\end{array}
$$

\section{Data Availability}

The data used to support the findings of this study are available from the corresponding author upon request.

\section{Conflicts of Interest}

The authors declare that they have no conflicts of interest.

\section{Acknowledgments}

This work was supported by the National Nature Science Foundation under Grant 62063011, Science and Technology Program of Science and Technology Department of Yunnan Province under Grant 202001AU070032, Scientific Research Fund of Yunnan Education Department under Grant 2019J0046, and Scientific Research Initial Fund for Introduction of Talent of Kunming University of Science and Technology under Grant KKSY201801019.

\section{References}

[1] H. Magalhães, J. Pombo, J. Ambrósio, and J. F. A. Madeira, "Rail vehicle design optimization for operation in a mountainous railway track," Innovative Infrastructure Solutions, vol. 2, no. 1, pp. 2-7, 2017.

[2] P. P. Wang, Y. Yang, B. Yi, W. Zeng, and T. Wang, "Robust optimization of high-speed rail vehicle suspension parameters based on vertical running stability," Journal of the Chinese
Society of Mechanical Engineers, vol. 40, no. 6, pp. 583-593, 2019.

[3] W. Liu, Y. Yang, P. Wang, X. Chen, and X. Wei, "Metamodelbased robust collaborative optimization for the suspension parameters of rail vehicles," Journal of the Chinese Institute of Engineers, vol. 42, no. 8, pp. 643-652, 2019.

[4] Y. He and J. McPhee, "Optimization of curving performance of rail vehicles," Vehicle System Dynamics, vol. 43, no. 12, pp. 895-923, 2005.

[5] P. Wang, X. Ma, J. Wang, J. Xu, and R. Chen, "Optimization of rail profiles to improve vehicle running stability in switch panel of high-speed railway turnouts," Mathematical Problems in Engineering, vol. 2017, Article ID 2856030, 13 pages, 2017.

[6] C. Dullinger, W. Struckl, and M. Kozek, "Simulation-based multi-objective system optimization of train traction systems," Simulation Modelling Practice and Theory, vol. 72, 2017.

[7] X. Sun, L. Chen, S. Wang, and X. Zhang, "Research on performance benefits in railway vehicle suspension employing inerter," Journal of The China Railway Society, vol. 39, no. 2, pp. 32-38, 2017.

[8] Y. He and J. McPhee, "Design optimization of rail vehicles with passive and active suspensions: a combined approach using genetic algorithms and multibody dynamics," Vehicle System Dynamics, vol. 37, no. 1, pp. 397-408, 2002.

[9] J. Huang, Y. Cao, and Y. W. Wang, "Adaptive proxy-based sliding mode control for a class of second-order nonlinear systems and its application to pneumatic muscle actuators," ISA Transactions, 2020.

[10] J. Huang, S. Ri, T. Fukuda, and Y. Wang, "A disturbance observer based sliding mode control for a class of underactuated robotic system with mismatched uncertainties," 
IEEE Transactions on Automatic Control, vol. 64, no. 6, pp. 2480-2487, 2019.

[11] J. Huang, M. Ri, D. Wu, and S. Ri, "Interval type-2 fuzzy logic modeling and control of a mobile two-wheeled inverted pendulum," IEEE Transactions on Fuzzy Systems, vol. 26, no. 4, pp. 2030-2038, 2018.

[12] D. Wu, C.-T. Lin, J. Huang, and Z. Zeng, "On the functional equivalence of TSK fuzzy systems to neural networks, mixture of experts, CART, and stacking ensemble regression," IEEE Transactions on Fuzzy Systems, vol. 28, no. 10, pp. 2570-2580, 2020.

[13] M. C. Smith, "Synthesis of mechanical networks: the inerter," IEEE Transactions on Automatic Control, vol. 47, no. 10, pp. 1648-1662, 2002.

[14] M. C. Smith and F. C. Wang, "Performance benefits in passive vehicle suspensions employing inerters," Vehicle System Dynamics, vol. 42, no. 3, pp. 235-257, 2004.

[15] A. Javidialesaadi and N. E. Wierschem, "An inerter-enhanced nonlinear energy sink," "Mechanical Systems and Signal Processing, vol. 129, pp. 449-454, 2019.

[16] W. M. Kuhnert, P. J. P. Gonçalves, D. F. Ledezma-Ramirez, and M. J. Brennan, "Inerter-like devices used for vibration isolation: a historical perspective," Journal of the Franklin Institute, vol. 358, no. 1, pp. 1070-1086, 2021.

[17] F. C. Wang, Y. C. Chen, and C. H. Lee, "Design and optimization of inerter layouts for a multi-layer building model," SICE, vol. 4, pp. 1076-1081, 2016.

[18] F.-C. Wang, M.-K. Liao, B.-H. Liao, W.-J. Su, and H.-A. Chan, "The performance improvements of train suspension systems with mechanical networks employing inerters," Vehicle System Dynamics, vol. 47, no. 7, pp. 805-830, 2009.

[19] F.-C. Wang and M.-K. Liao, "The lateral stability of train suspension systems employing inerters," Vehicle System Dynamics, vol. 48, no. 5, pp. 619-643, 2010.

[20] F.-C. Wang, M.-R. Hsieh, and H.-J. Chen, "Stability and performance analysis of a full-train system with inerters," Vehicle System Dynamics, vol. 50, no. 4, pp. 545-571, 2012.

[21] J. Z. Jiang, A. Z. Matamoros-Sanchez, A. Zolotas, R. M. Goodall, and M. C. Smith, "Passive suspensions for ride quality improvement of two-axle railway vehicles," Proceedings of the Institution of Mechanical Engineers, Part F: Journal of Rail and Rapid Transit, vol. 229, no. 3, pp. 315-329, 2015.

[22] J. Z. Jiang, A. Z. Matamoros-Sanchez, R. M. Goodall, and M. C. Smith, "Passive suspensions incorporating inerters for railway vehicles," Vehicle System Dynamics, vol. 50, pp. 263-276, 2012.

[23] W. M. Zhai, Vehicle-Track Coupled Dynamics, Science Press and Springer Nature Singapore Pte Ltd, Singapore, 2020.

[24] S. Timoshenko, D. H. Young, and W. Weaver Jr., Vibration Problems in Engineering, Wiley, Hoboken, NJ, USA, 4th ed edition, 1974.

[25] H. H. Jenkins, J. E. Stephenson, and G. A. Clayton, "The effect of track and vehicle parameters on wheel/rail vertical dynamic forces," Railway Engineering Journal, vol. 3, no. 1, pp. 2-16, 1974.

[26] H. Katsu, Random Vibration Analysis, Seismological Press, Beijing, China, 1977.

[27] W. M. Zhai, "Two simple fast integration methods for largescale dynamic problems in engineering," International Journal for Numerical Methods in Engineering, vol. 39, no. 24, pp. 199-214, 1996. 